\title{
Application of J2EE Technology in the Construction and Implementation of E-learning Platform
}

\author{
Min Zhang, Qiying Wang and Xueke Zhang \\ Northwest University, Xi'an, Shaanxi 710127, China \\ zhangmin@nwu.edu.cn
}

Keywords: J2EE Technology; E-learning Platform; Application

\begin{abstract}
With the continuous development of computer and network technology, the degree of informationization of society is getting higher and higher, and information technology is gradually infiltrating into various fields. Network teaching can use computer to access computer information resources all over the world, and can realize teachers and networks through the network. Students conduct more extensive exchanges. This paper studies and discusses the construction process of a network teaching platform based on J2EE technology. The E-learning system based on J2EE architecture is aimed at the problems existing in traditional teaching. Combined with the mainstream mode of network teaching, it adopts the more mature network technology, discusses the requirements and functional characteristics of the system in detail, and finally proposes a new network. Teaching system solutions.
\end{abstract}

\section{E-learning Feature}

E-Learning was first proposed in North America in 1990, and its basic content is based on network technology and information technology to support learning activities. The definition of E-Learning refers to the learning and teaching activities through the Internet or other digital content. It makes full use of the learning environment provided by modern information technology with new communication mechanism and rich resources to realize a new learning style: The learning style will change the role of teachers in traditional teaching and the relationship between teachers and students, thus fundamentally changing the structure of teaching and the nature of education.

(1) Asynchronous communication, including online discussion forums and emails within the course. Through asynchronous communication tools, students and teachers can communicate without having to meet or at the same time[1].

(2) Synchronous communication, including text-based live chat and online audiovisual conferences. To communicate synchronously, students and teachers must log in to the same location on the web to communicate in a virtual face-to-face mode.

(3) File sharing. This feature enables students and students, as well as students and teachers, to share information and collaborate on the Internet. For example, students can submit assignments directly to the teacher through file sharing, and the teacher can easily return the corrected assignments to the students[2] .

(4) Working group, which is particularly suitable for group project research. Workgroup functions include group sites, group discussion areas, and group file sharing areas. If students need to do group project research, they can pass their work to a specific file-sharing area on the course website so that each member of the group can easily see the work of other members.

(5) Electronic whiteboard. This tool is especially popular in math and natural science courses because students and teachers can simultaneously view a mathematical formula or other graphic on the screen, and can add and modify it at the same time. Students can save the pictures on the electronic whiteboard for future reference.

\section{The Development of J2EE}

J2EE (Java Platform Enterprise Edition) is a new concept model introduced by Sun Microsystems of the United States, which has incomparable advantages compared with the traditional Internet 
application model. Many companies today need to expand their business scope, reduce their own operating costs, and reduce the response time between them and their customers. This requires a simple and fast service between enterprises, partners and employees. J2EE provides a component-based approach and a multi-tiered distributed application model, a consistent security model, and flexible transaction control. J2EE not only enables rapid rollout of creative customer solutions, but because of its cross-platform, component-based features, it also ensures that the solution is not tied to any vendor's products and APIs.[2] At present, J2EE has been widely favored by enterprise application personnel.The following is a typical four-tier structure of J2EE, as shown in Figure 2.

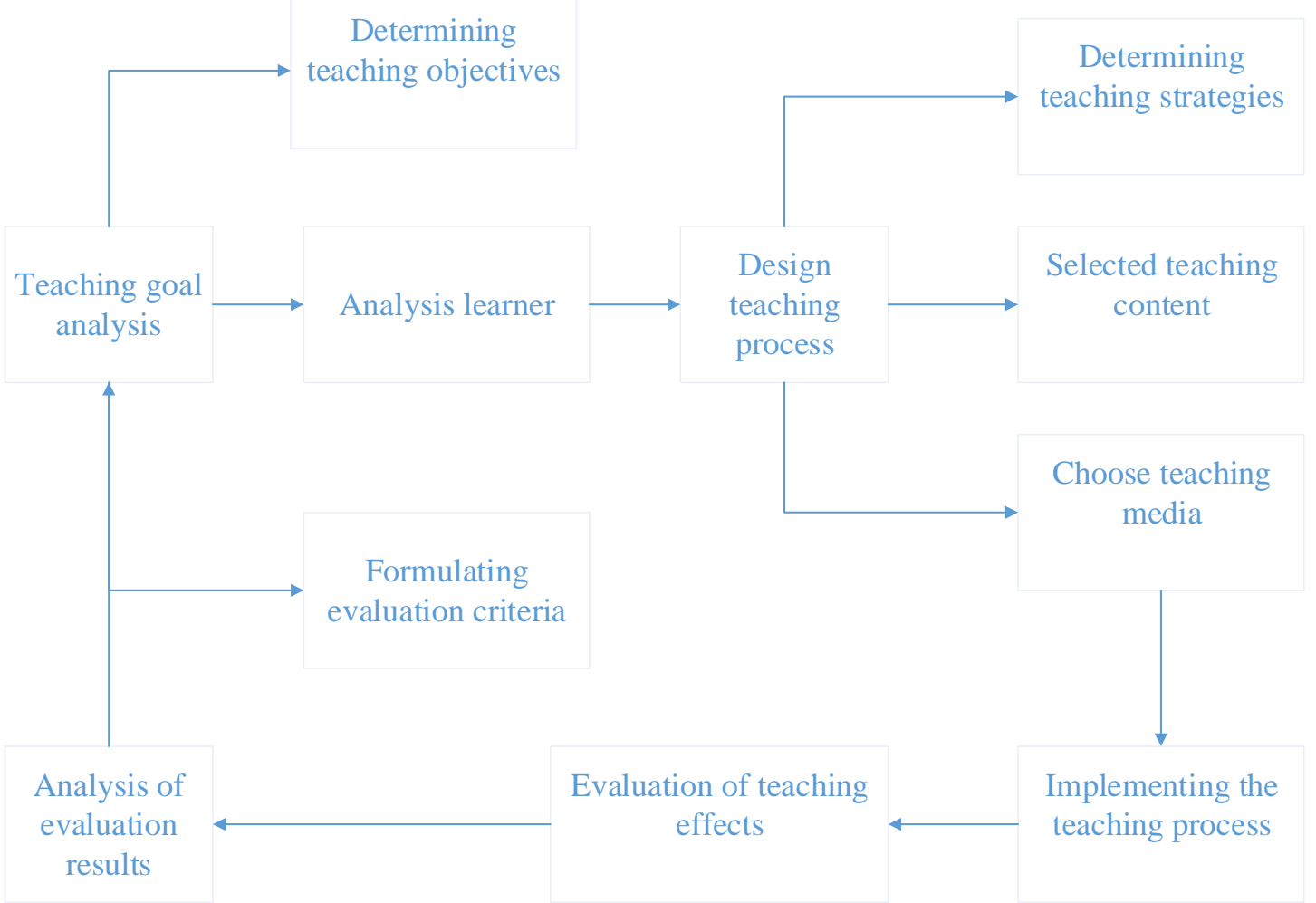

(1) Customer layer

Figure 1 E-learning teaching design flow chart

The user's perception of an enterprise application is closely related to the behavior of the client layer. The client layer is responsible for sending the user's request to the server and presenting the server's return results to the user. The J2EE platform supports multiple types of users, and its clients can be web clients, applets or client applications. The web client typically runs in a browser and uses the browser's services to display the content provided by the web layer. Among these customers, the user interface is generated by the web layer on the server side and communicates using HTML[3].

(2) Web layer

The web layer is for web-based applications. The web tier component can support the generation of dynamic web pages in a portable, cross-platform manner. Their primary role is to respond to web client requests, accept and validate incoming data, pass the data to the business logic components of the business layer, and return the results of the business layer to the user.

(3) Commercial layer

The business layer is often referred to as the EJB layer. The business layer accommodates application-related business logic and system-level services such as transaction management, concurrency control, and security. The EJB receives data from the client application, processes the data accordingly, and sends the data to the EIS (Enterprise Information System) layer store. On the other hand, EJB is also responsible for retrieving data from storage and returning the data to the 
client application.

(4) EIS layer

EIS is the enterprise information system layer, which includes various enterprise infrastructures, such as enterprise resource planning (ERP), customer relationship management (CRM), database systems, etc. Enterprise applications require access to applications running on EIS, J2EE Many technologies are provided to access the EIS layer, the most typical of which is to use JDBC technology to access the database.[3]

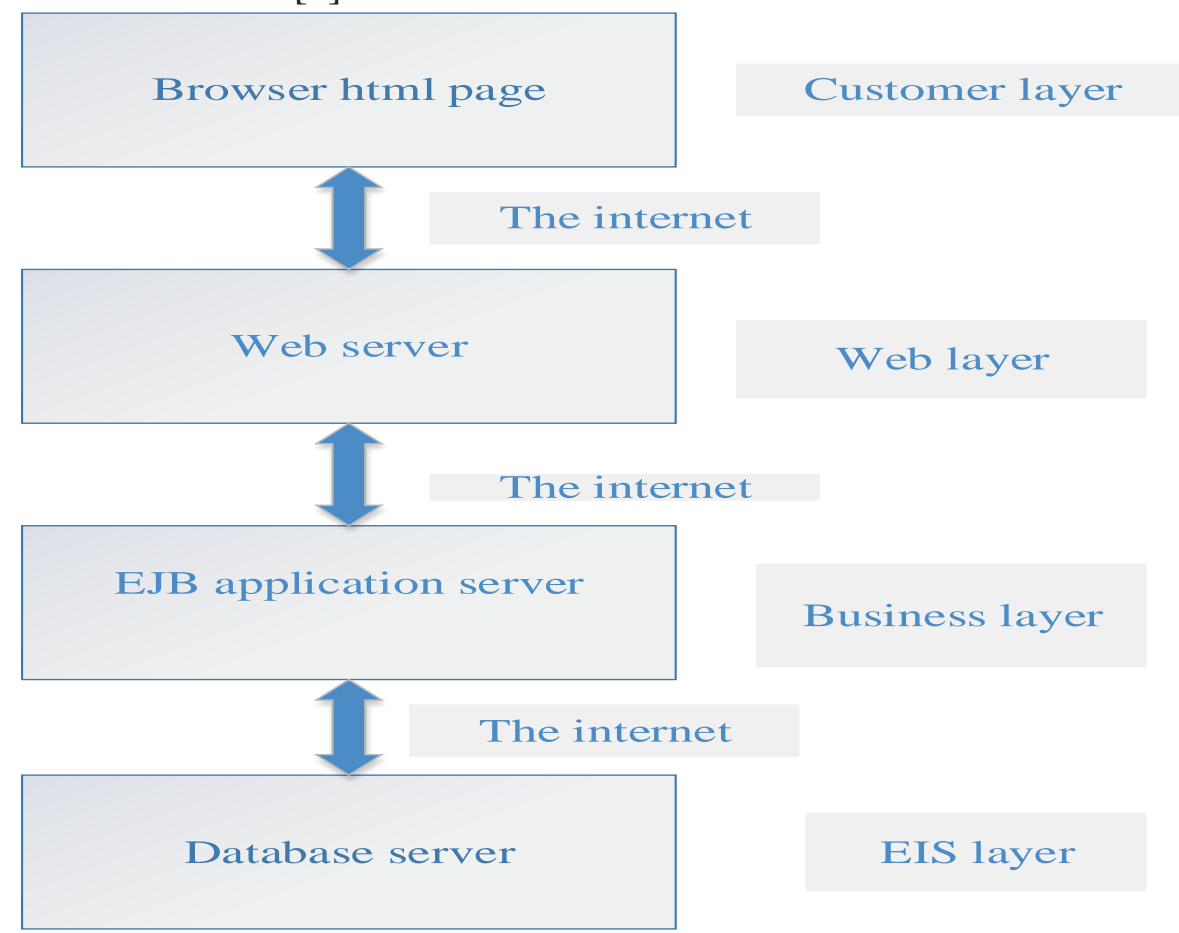

Figure 2 J2EE multi-tier application model

\section{Construction Analysis of the E-Learning Platform}

(1) User requirements

A complete online teaching platform should consist of four subsystems: online teaching support system, online educational management system, online course development tools and online teaching resource management system.[4]

(2) Analysis of system function structure

(1) Online teaching support system

The online teaching support system mainly includes online publishing of courses, support for teacher teaching and support for student learning in the teaching process, and management of teaching activities.[5]

(2) Online educational management system

Online education management mainly includes course management and student status management. The online educational management system should be well compatible with existing school educational management systems.

(3) Online course development tools

Online course development tools mainly complete the presentation of online course content, support the design of basic teaching logic, and provide some facilities and tools to facilitate and accelerate the development of online courses 


\section{Online teaching \\ support system}
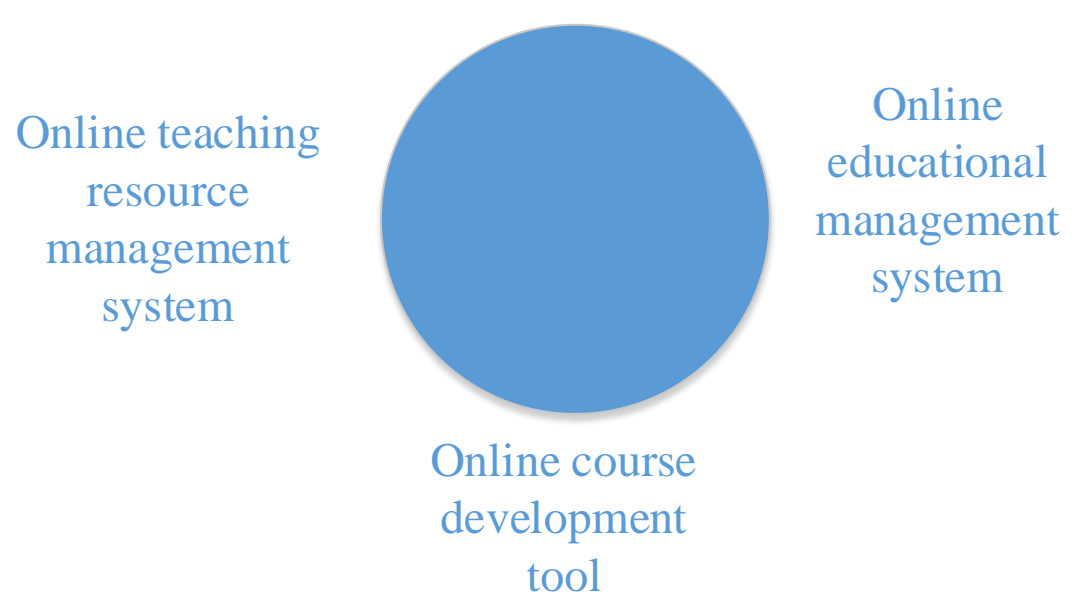

Figure 3 Functional block diagram of the E-learning platform

(4) Teaching resource management module

The online teaching resource management system mainly refers to the management of the media material library, the test question database, the personnel archive, the courseware library, and the literature database[4].

\section{Conclusion}

The paper introduces a relatively common E-leaming system construction method under the J2EE platform. By studying the popular J2EE technology and combining some practices of project development process management, this paper proposes a solution based on J2EE framework and realizes network teaching system through process management. In a certain sense, the thesis is not only a summary of the research process of the subject, but also an exploration of the comprehensive application of relevant theories and technologies.

\section{References}

[1]Li Y M, Bai L, Wang L, et al. Design and Implementation of the Logistics Management System Based on J2EE Technology[J]. Advanced Engineering Forum, 2012, 6-7:379+384.

[2]Yan L, Tang X F. Design and Implementation of E-Learning System Based on J2EE[J]. Electronic Technology ,2005, 3(3):222+225.

[3]He L, Chen Y. Design and implementation of Web Content Management System by J2EE-based three-tier architecture: Applying in maritime and shipping business[C]// The, IEEE International Conference on Information Management and Engineering. IEEE, 2010:513+517.

[4]Fu C, Zhuang C, Gao X, et al. Research on and Construction of Network Question-Answering System[J]. International Journal of Digital Content Technology \& Its Applications, 2012, $6(17): 279+286$.

[5]Lin N, Li D, Dong T, et al. A New Framework for Designing E-Government Procurement in China Based on Ontology and Business Component[J]. Journal of Service Science \& Management, 2010, 3(3):298+308. 